\title{
Hipomineralización incisivo molar, una condición clínica aún no descrita en la niñez costarricense
}

\section{Molar Incisor Hipomineralization, a Clinical Entity Never Described Before in Costa Rican Children}

\author{
Joseph Ulate Jiménez DDS'; Sylvia Gudiño Fernández DDS, MPH² \\ 1. Especialista en Odontopediatría. Posgrado en Odontopediatría. Departamento de Odontología Social. \\ Profesor Adjunto. Facultad de Odontología. Universidad de Costa Rica, Costa Rica. \\ 2. Especialista en Odontopediatría. Master of Philosophy (Dentistry). Posgrado en Odontopediatría. Departamento \\ de Odontología Social. Profesora Catedrática. Facultad de Odontología. Universidad de Costa Rica, Costa Rica. \\ Autor para correspondencia: Dr. Joseph Ulate Jiménez - julatej@gmail.com \\ Recibido: 01-X-2013 Aceptado: 02-II-2014_ Publicado Online First: 20-XI-2015
}

DOI: http://dx.doi.org/10.15517/ijds.v0i0.21482

RESUMEN

El esmalte dental es un tejido único, altamente mineralizado y de origen ectodérmico, que una vez formado, se caracteriza por la ausencia de actividad metabólica. Ello determina que si se presentan disturbios durante su desarrollo, éstos se pueden manifestar como defectos permanentes en los dientes cuando erupcionan. El presente artículo reporta los hallazgos más notables publicados en la literatura científica durante la última década acerca de la Hipomineralización Incisivo Molar, refiriéndose a su denominación, propuestas de clasificación, signos y síntomas, histología y diagnóstico diferencial.

\section{PALABRAS CLAVE}

Hipomineralización Incisivo Molar, HIM, Clasificación, Hallazgos clínicos, Epidemiología, Diagnóstico diferencial.

\section{ABSTRACT}

Dental enamel is an unique, highly mineralized tissue from ectodermal origin, characterized by the absence of metabolic activity once its formation is completed. This fact determines that when disturbances occur during its development, defects will be present in the permanent tooth at eruption. This article reports the most important findings published in the scientific literature over the last decade about Molar Incisor Hypomineralization, denomination, histology, classification, signs and symptoms, epidemiology, histology and differential diagnosis.

\section{KEYWORDS}

Molar Incisor Hypomineralization, MIH, Classification, Clinical findings, Epidemiology, Differential diagnosis.

ULATE J. \& GUDIÑO S., 2015: Hipomineralización incisivo molar, una condición clínica aún no descrita en la niñez costarricense.-ODOVTOS-Int. J. Dental Sc., 17-3 (September-December): 15-28. 


\section{INTRODUCCIÓN}

Las alteraciones que se producen en la amelogénesis, durante la fase inicial de secreción de la matriz de las piezas dentarias, pueden provocar defectos estructurales cuantitativos 0 hipoplasias, que se asocian con un espesor localizado y reducido del esmalte, mientras que si los disturbios afectan los procesos de maduración o de mineralización, se traducen en defectos cualitativos 0 hipomineralizaciones (1), también llamados opacidades (2).

HALLAZGOS HISTOLÓGICOS DE LA HIPOMINERALIZACIÓN INCISIVO MOLAR (MIH)

El esmalte es un tejido altamente mineralizado que es secretado por el ameloblasto y diferenciado de la zona del epitelio interno del órgano del esmalte. La amelogénesis se inicia una vez formadas las primeras capas de la dentina, cuando hay secreción de la matriz del esmalte y después aparecen -dentro de esa matriz- los cristales de hidroxiapatita.

La hipomineralización es un defecto cualitativo del esmalte en el que la maduración y la mineralización del esmalte se presentan de manera incompleta bajo una superficie intacta al momento de la erupción. Los cristales parecen estar menos compactados y organizados en las áreas porosas, lo que sugiere una alteración en la fase de maduración (3). Por razones no del todo esclarecidas, se produce una alteración que causa la retención de proteínas, lo que interfiere con la formación de los cristales, al faltar el espacio necesario para la deposición de los minerales. Inicialmente, se produce entonces un defecto en la composición, pero no en el espesor del tejido, viéndose así negativamente alteradas las propiedades mecánicas del esmalte de dureza y módulo de elasticidad (4). La concentración mineral del esmalte de las piezas afectadas disminuye desde el límite amelodentinal hacia la zona subsuperficial del esmalte, situación opuesta a la que se presenta en el esmalte normal (5).
Las opacidades son asimétricas, bien delimitadas, no afectan la zona gingival, presentan alta porosidad y varían en coloración: las de la gama de colores del amarillento al amarillo-marrón, se deben a un daño irreversible del ameloblasto, mientras que las opacidades con variaciones de color del blanco al amarillo-crema corresponden más bien a un ameloblasto que logró recuperarse de la alteración (4). (Figuras 1, 2, 3, 4 y 5).

Estudios histológicos de molares con HIM sin caries indican que la pulpa de las piezas dentales con la condición presenta cierto grado de inflamación (6), la que puede ocasionar hipersensibilidad, aparentemente provocada por la penetración de las bacterias en los túbulos dentinarios a través del esmalte hipomineralizado aún intacto, que produce reacciones inflamatorias pulpares (7).

\section{DENOMINACIÓN}

Koch et al. (1987) utilizaron el término Hipomineralización Idiopática del Esmalte en Suecia a fines de la década de los años 70 para describir la condición, mientras que Hipomineralización Incisivo Molar (Molar Incisor Hypomineralization MIH por sus siglas en inglés, HIM en español) fue acuñado por Weerheijm y Mejàre en 2001 y aceptado en 2003 por la Academia Europea de Odontopediatría en Atenas, Grecia, utilizándose desde entonces para describir una condición caracterizada por la hipomineralización -de origen sistémico- del esmalte, que afecta desde una hasta las cuatro primeras molares permanentes, y que se puede asociar con la presencia de opacidades o defectos en los incisivos permanentes (8). La afectación simultánea de molares e incisivos se considera la forma más severa de hipomineralización.

Las anteriores no son las únicas propuestas reportadas en la literatura para denominar la condición, de modo que, entre otros, recibe nombres como: 
- Hipoplasia intrínseca del esmalte.

- Hipomineralización idiopática del esmalte.

- Opacidades del esmalte no-fluoróticas.

- Opacidades del desarrollo.

- Opacidades demarcadas, difusas o confluentes.

- Molares de queso o "cheese molars".

- Manchas opacas (9) (10).

Desde la pasada década la HIM es reconocida como una entidad clínica en algunos sitios del mundo; sin embargo, en muchos países su prevalencia es aún desconocida. Al respecto, Weerheijm y Mejàre indagaron en Europa (2003) acerca del reconocimiento de la condición en 31 países, obteniendo una abrumadora respuesta positiva (97\%) (11). Posteriormente, Crombie et al. (2009) en Nueva Zelandia y Australia utilizaron un cuestionario para valorar el conocimiento y la percepción de los odontopediatras acerca de la condición (12). En Latinoamérica, Biondi y Cortese (2009) informaron que la HIM es ampliamente reconocida como entidad clínica en las diferentes universidades latinoamericanas y que dada la actual carencia de información, a nivel regional hay interés de realizar estudios epidemiológicos (1).

Existe consenso internacional acerca de la recomendación de que para su diagnóstico, el examen clínico debe efectuarse después de los 8 años de edad, una vez que los incisivos anteriores superiores e inferiores y las primeras molares permanentes han completado su erupción (13).

\section{CLASIFICACIONES DE HIM}

Según la propuesta de Mathu-Muju y Wright (2006), se diferencian tres grados de hipomineralización:leve, moderada y severa, cuyas características se describen en el Cuadro 1(14).
Cuadro 1. Clasificación de lesiones de HIM y características clínicas según los distintos grados de severidad.

\section{Clasificación Características}

\begin{tabular}{ll}
\hline $\begin{array}{l}\text { Grado 1: Leve } \\
\text { (Figuras 1 y 2) }\end{array}$ & $\begin{array}{l}\text { Opacidades aisladas bien delimitadas en áreas } \\
\text { sin carga o estrés masticatorio. Ausencia de } \\
\text { pérdida de los tejidos duros. No hay caries } \\
\text { asociada con el defecto de esmalte. No hay } \\
\text { hipersensibilidad. Cuando se presenta en los } \\
\text { incisivos, la alteración es leve. }\end{array}$ \\
Opacidades bien delimitadas en incisivos o \\
Grado 2: & $\begin{array}{l}\text { molares en el tercio oclusal y/o incisal que } \\
\text { afecta una o dos superficies, sin involucrar las }\end{array}$ \\
(Figuras 3, 4 y 5) & $\begin{array}{l}\text { cúspides y sin fractura del esmalte al erupcionar, } \\
\text { aunque puede ocurrir post-eruptivamente } \\
\text { debido a la función. Presencia de restauraciones }\end{array}$ \\
& $\begin{array}{l}\text { atípicas intactas. Hay compromiso estético y la } \\
\text { sensibilidad es normal. }\end{array}$ \\
Grado 3: Severa & $\begin{array}{l}\text { Pérdida post-eruptiva del esmalte y fracturas. } \\
\text { (Figura 6) }\end{array}$ \\
& $\begin{array}{l}\text { Presencia de caries extensas asociadas } \\
\text { al esmalte defectuoso y/0 presencia de } \\
\text { restauraciones atípicas defectuosas, con }\end{array}$ \\
& compromiso de la estética e hipersensibilidad.
\end{tabular}

Según Jans y colaboradores (2011) la prevalencia de HIM en infantes chilenos es de $16.8 \%$, con la siguiente distribución de severidad: $57 \%$ mostrósignos severos, 20\% moderados y $23 \%$ leves (15). La severidad de HIM no solo varía entre los distintos pacientes, sino también entre los diferentes dientes del mismo paciente, por lo que aún en el caso de que todos los primeros molares estén afectados, presentan diversos grados de compromiso estructural $(16,17,18)$.

En relación con la clasificación de las lesiones de HIM según su color y severidad, Biondi et al. (2010) proponen utilizar la que se describe en el Cuadro 2 (1). 
Cuadro 2. Categorización de la severidad de lesiones de HIM según su color.

\begin{tabular}{clc}
\hline Aspecto & \multicolumn{1}{c}{ Características } & Código \\
\hline Normal & & 0 \\
$\begin{array}{c}\text { Blanco crema: } \\
\text { Leve }\end{array}$ & $\begin{array}{l}\text { Menos porosas. Se localizan } \\
\text { en el interior del esmalte }\end{array}$ & 1 \\
$\begin{array}{c}\text { (Figuras 1, 2 y 3) } \\
\text { (Comes, 2007). }\end{array}$ & \\
$\begin{array}{c}\text { Amarillo-marrón: } \\
\text { Moderado }\end{array}$ & $\begin{array}{l}\text { Son más porosas y ocupan } \\
\text { todo el espesor del esmalte }\end{array}$ & 2 \\
(Figura 4 y 5) & (Comes, 2007). \\
Pérdida del & $\begin{array}{l}\text { El esmalte hipomineralizado } \\
\text { esmalte: Severo fractura debido a su } \\
\text { (Figura 6) }\end{array}$ & $\begin{array}{l}\text { fragilidad y escaso espesor, } \\
\text { desprotegiendo la dentina. }\end{array}$ \\
& \\
\hline
\end{tabular}

También es importante determinar en cada superficie dental, la extensión de los tejidos afectados por HIM. Para ello,Biondi y colaboradores (2010) utilizan la siguiente clasificación (Cuadro 3) (1):

Cuadro 3. Registro de la extensión de las lesiones de MIH.

\section{Extensión}

Código

No afectada

0

Menos de 1/3 de la superficie dental

1

Más de 1/3 pero menos de 2/3 de la superficie dental

2

Más de 2/3 de la superficie dental

3
El clínico debe tener presentes varias características asociadas con la alteración para estar en condiciones de brindar a los pacientes un manejo óptimo e integral.

\section{HISTORIA CLÍNICA}

Es muy importante indagar acerca de eventos médicos 0 ambientales ocurridos alrededor del nacimiento y/o durante los tres primeros años de vida, ya que pueden indicar relación con alguno de los posibles factores etiológicos que se mencionan en la sección correspondiente.

SÍNTOMAS

Un rasgo característico expresado por los pacientes con HIM es la presencia de sensibilidad dental a los estímulos térmicos, químicos y mecánicos, especialmente durante el cepillado dental 0 inclusive, durante la simple inspiración de aire (19). La sensibilidad depende de la severidad de la condición, lo que determina que es mayor en los individuos con HIM moderada o severa, pudiendo incluso persistir después de la colocación de la anestesia local (10). En los pacientes pediátricos la hipersensibilidad puede interferir con los tratamientos dentales, los que pueden llegar a ser muy dolorosos (20) y consecuentemente, acarrear problemas de conducta como resultado del miedo y la ansiedad del infante (19). La hipersensibilidad favorece la acumulación de biofilm dental, lo que aunado a la fragilidad del esmalte, incrementa la probabilidad de aparición de lesiones cariosas de rápido avance, gran destrucción coronaria y hasta la pérdida del diente $(10,21,12)$. También se ha reportado que la calidad de vida de los 
niños y adolescentes que sufren la condición se ve afectada con una autoimagen desfavorable, baja autoestima y que se exponen más al acoso escolar, lo que en conjunto, puede perjudicar su interacción social (44).

\section{SIGNOS: CARACTERÍSTICAS CLIIIIICAS DE HIM}

El esmalte es el tejido dental en el que se manifiesta la HIM, caracterizándose por la presencia de opacidades fácilmente distinguibles del esmalte sano gracias a la delimitación de la zona afectada, y a que presenta variaciones en su coloración en un rango de tonos que van desde el blanquecino-cremoso hasta el marrónamarillento (22). Clínicamente se observa una anomalía en la translucidez del esmalte en áreas demarcadas, debido a la pérdida del contenido mineral, que no afecta su espesor $(21,14,23)$. Los defectos varían en forma y tamaño según el grado de hipomineralización (14), localizándose preferentemente en los dos tercios incisales $\mathrm{u}$ oclusales de la corona del diente afectado. Esta característica incide en el grado de deterioro de la estructura dental, ya que en las regiones aledañas al tercio gingival, la alteración del esmalte es menor $(14,10,8)$.

En relación con las piezas dentales más frecuentemente afectadas, la HIM puede afectar desde una sola hasta las cuatro primeras molares permanentes de manera simultánea. Existe correlación entre la cantidad de superficies afectadas y la severidad de las lesiones (43). No siempre la alteración se manifiesta en los incisivos, pero pueden llegar a afectarse en más del $30 \%$ de los casos, sobre todo los centrales superiores (10), en los que por lo general no se presenta pérdida estructural (19) aún cuando la lesión se puede extender ampliamente en la superficie vestibular (24). Ello representa un importante problema estético, debido a la visibilidad de las opacidades (25).
Odontopediatras argentinos (1) estudiaron las características clínicas de HIM en 98 niños, reportando que las piezas dentales más afectadas siguen el siguiente orden: molares inferiores, molares superiores, incisivos centrales superiores, incisivos centrales inferiores, incisivos laterales superiores e incisivos laterales inferiores. De los infantes con la condición, el $80.61 \%$ presentó uno ó más incisivos afectados, mientras que el $41.83 \%$ mostró defectos simultáneos en los cuatro molares, de los que el 44.5\% reportó sensibilidad. En relación con las superficies más afectadas, figuran en primer lugar las vestibulares y oclusales de las piezas inferiores, y en segundo término las mismas superficies en las superiores. En los incisivos, las caras más afectadas son las vestibulares de los centrales superiores, seguidas por las mismas superficies en los centrales inferiores. Contrariamente, en otros reportes la arcada más afectada es el maxilar superior y se ha encontrado relación directa entre el número de dientes afectados (entre 2 y 5.7) y la severidad de la condición. No se han descrito diferencias en referencia con el género(26, 27), asícomo tampoco con la raza (28).

Niños chilenos de 6 a 13 años portadores de HIM presentaron un promedio de 3.6 molares afectados, siendo el diente más frecuentemente dañado el primer molar superior derecho (93\%). De los incisivos, los centrales superiores (derecho $55 \%$; izquierdo 50\%) fueron las piezas dentales en las que se concentraron casi todos los defectos (15). En Alemania, un estudio reciente reportó una alta prevalencia de la condición en primeras molares permanentes (71\%) y menos afectación en incisivos centrales maxilares (15\%). De las lesiones encontradas, el $82 \%$ se clasificaron como opacidades bien delimitadas, mientras que el restante 18\% correspondió a defectos severos del esmalte. En molares, la superficie afectada con mayor frecuencia fue la oclusal (72\%), mientras que en el $75 \%$ de los incisivos fue la vestibular (43). 
Más recientemente, lesiones como las descritas para HIM se han reportado en otras piezas dentales como segundas molares temporales, cúspides de caninos permanentes, segundas molares permanentes y premolares (29).

\section{OTROS CRITERIOS DIAGNÓSTICOS}

Con frecuencia se produce la fractura del esmalte después de la erupción asociada con la existencia de una opacidad previa, sobre todo en las superficies oclusales de molares, al establecerse la total oclusión.

\section{DIAGNÓSTICO DIFERENCIAL}

Es frecuente que los odontólogos confundan la pérdida post-eruptiva de la estructura dental de los estados más severos de HIM con lesiones cariosas, brindando a la condición el abordaje inadecuado, por lo que el diagnóstico diferencial es de suma importancia. La presencia de restauraciones de localización y extensión atípicas, sobre todo en pacientes con bajo índice de caries, es otro elemento que puede contribuir en la consecución del logro del correcto diagnóstico de la condición.

Uno de los aspectos más relevantes de la clínica de la HIM es que raramente los molares se encuentran igualmente comprometidos y que nunca afecta todos los dientes presentes; es decir, la condición nunca es generalizada (13).

El diagnóstico diferencial debe tomar en cuenta las diferencias entre las opacidades, la caries dental y la fluorosis (Cuadro 4), así como también las siguientes condiciones (30):

- Amelogénesis imperfecta: suele afectar ambas denticiones. Patrón hereditario correlacionado. Afecta todos los dientes presentes.
- Alteración ocasionada por un factor local de larga data (Diente de Turner por ejemplo).

- Hipoplasias: pérdida cuantitativa de la estructura dental. El diagnóstico diferencial es difícil de establecer, ya que en HIM puede ocurrir pérdida de la estructura adamantina al entrar las piezas dentales en función.

\section{ETIOLOGÍA}

El período crítico para la aparición de HIM son los tres primeros años de vida, ya que es durante esta etapa que ocurre la mineralización de la corona de las primeras molares, incisivos superiores e inferiores y caninos permanentes $(26,4)$. En un estudio de Lygidakis et al. (2008) se reportó que el $87 \%$ de los infantes con HIM presentaban potencial etiología de origen médico durante los períodos pre, peri y post natal, y que tan solo el $12 \%$ de los casos de HIM no se relacionaron con la historia médica (27).

A pesar de la investigación disponible en la actualidad, no se conoce un factor etiológico inequívoco que ocasione la condición (12), aunque entre las posibles causas se han sugerido las de tipo ambiental y/o sistémico, entre las que destacan:

- Desórdenes 0 alteraciones respiratorias ocurridos durante los primeros 3 años de vida, entre los que destacan infecciones de oídos (31), otitis media (32), infecciones respiratorias (1).

- Ingesta de leches especiales (1).

- Administración de antiinflamatorios AINES no esteroideos, habitualmente ibuprofeno y paracetamol (1).

- Predisposición genética $(33,34)$.

- Procesos que conllevan alta fiebre, especialmente durante el primer año de vida (31).

- Factores prenatales: prematuridad, bajo peso al nacer, escasez de oxígeno en el momento del parto, 
bajo peso al nacer, partos complicados, nacimiento pretérmino/semanas de gestación $(35,12)$.

- Exposición a dioxinas y a policlorobifenilos (PCB), compuestos presentes en las mamaderas y envases plásticos, que quedan incorporados en los alimentos luego de ser expuestos al calor, congelados 0 utilizados en el microondas (36). Se asocian con lactancia materna prolongada en niños cuyas madres tuvieron alta exposición a los elementos antes descritos (37).

- Enfermedad celiáca (38).

- Asma (39).

- Neumonía $(32,39)$.

- Uso antibióticos (31, 40).
En relación con el último punto, un estudio clínico experimental de Laisi et al. en Helsinski, Finlandia estableció una asociación clínica entre HIM y el uso de algunos antibióticos durante los primeros 3 años de vida: amoxicilina en primer lugar y en segundo, la raramente prescrita eritromicina; además, experimentalmente se encontraron alteraciones en el esmalte embrionario de ratas expuestas a la amoxicilina (40).

En la actualidad el consenso indica que es más bien la conjunción de una serie de los factores descritos lo que incrementa el riesgo de su aparición (41). 
Cuadro 4. Diagnóstico diferencial de caries dental, fluorosis y defectos del desarrollo de origen no fluorótico (42).

TF: Thylstrup y Fejerskov

\begin{tabular}{|c|c|c|c|c|c|c|}
\hline & \multicolumn{2}{|c|}{ Caries Dental } & \multicolumn{2}{|c|}{ Fluorosis Dental } & \multicolumn{2}{|c|}{$\begin{array}{c}\text { Defectos del Desarrollo no } \\
\text { Fluoróticos }\end{array}$} \\
\hline & No cavitada & Cavitada & $\begin{array}{c}\text { Muy leve a } \\
\text { moderada } \\
\text { (Índice TF 1-7) }\end{array}$ & $\begin{array}{c}\text { Severa } \\
\text { (Índice TF 5-9) }\end{array}$ & $\begin{array}{l}\text { Opacidad/ } \\
\text { Hipominera- } \\
\text { lización }\end{array}$ & Hipoplasia \\
\hline Características & $\begin{array}{l}\text { Lesión activa: } \\
\text { tizosa; rugosa al } \\
\text { sondaje. } \\
\text { Lesión inactiva: } \\
\text { brillante; lisa al } \\
\text { sondaje. }\end{array}$ & $\begin{array}{l}\text { Lesión activa: } \\
\text { cavidad con } \\
\text { dentina expuesta; } \\
\text { blanda al sonaje. } \\
\text { Lesión inactiva: } \\
\text { cavidad con } \\
\text { dentina expuesta; } \\
\text { dura al sondaje. }\end{array}$ & $\begin{array}{l}\text { Suave/brillante } \\
\text { (semejante a una } \\
\text { perla). }\end{array}$ & $\begin{array}{l}\text { Defectos } \\
\text { superficiales } \\
\text { varían desde } \\
\text { una pérdida } \\
\text { localizada de } \\
\text { esmalte } \\
\text { (formación de } \\
\text { fosa) hasta la } \\
\text { pérdida masiva. } \\
\text { Consistencia } \\
\text { dura al sondaje } \\
\text { (puede romperse } \\
\text { el esmalte). }\end{array}$ & Suave/brillantes. & $\begin{array}{l}\text { Defecto } \\
\text { superficial } \\
\text { con márgenes } \\
\text { redondeados que } \\
\text { varían en forma } \\
\text { y profundidad } \\
\text { (esféricos } 0 \\
\text { irregulares). } \\
\text { Duro o áspero al } \\
\text { sondaje. }\end{array}$ \\
\hline Color & $\begin{array}{l}\text { Lesión activa: } \\
\text { blanquecina a } \\
\text { café claro. } \\
\text { Lesión inactiva: } \\
\text { blanquecina a } \\
\text { café/negro. }\end{array}$ & $\begin{array}{l}\text { Amarillento a } \\
\text { café negruzco. }\end{array}$ & $\begin{array}{l}\text { Blanquecina } \\
\text { (opaca). Grados } \\
\text { ligeros pueden } \\
\text { teñirse secunda- } \\
\text { riamente. }\end{array}$ & $\begin{array}{l}\text { Puede presentar } \\
\text { secundariamente } \\
\text { pérdida de color. }\end{array}$ & $\begin{array}{l}\text { Blanquecino } \\
\text { (opaco) a } \\
\text { amarillo cremoso } \\
\text { parduzco. }\end{array}$ & $\begin{array}{l}\text { Amarillento } 0 \\
\text { parduzco. }\end{array}$ \\
\hline $\begin{array}{c}\text { Características } \\
\text { de } \\
\text { demarcación }\end{array}$ & $\begin{array}{l}\text { Lesión activa: } \\
\text { usualmente } \\
\text { íntimamente } \\
\text { demarcada } \\
\text { (sitios de } \\
\text { retención de } \\
\text { biofilme dental). } \\
\text { Lesión inactiva: } \\
\text { bien demarcada } \\
\text { o con bordes } \\
\text { difusos. }\end{array}$ & $\begin{array}{l}\text { Lesión inactiva: } \\
\text { sin demarcación } \\
\text { nítida de los } \\
\text { márgenes de la } \\
\text { lesión. }\end{array}$ & $\begin{array}{l}\text { Estrías blancas } \\
\text { reflejando } \\
\text { patrón de } \\
\text { periquematíes. } \\
\text { En casos } \\
\text { ligeros pueden } \\
\text { aparecer zonas } \\
\text { con apariencia } \\
\text { nevada a nivel } \\
\text { de cúspides/ } \\
\text { bordes incisales } \\
\text { y marginal. }\end{array}$ & $\begin{array}{l}\text { Formación de } \\
\text { fosas. }\end{array}$ & $\begin{array}{l}\text { Bien demarcados } \\
\text { (a menudo } \\
\text { esféricos). } \\
\text { Pueden estar } \\
\text { rodeados por un } \\
\text { halo delgado y } \\
\text { traslúcido. }\end{array}$ & $\begin{array}{l}\text { Sin demarcación } \\
\text { definida de } \\
\text { márgenes de la } \\
\text { lesión. } \\
\text { Usualmente } \\
\text { sigue el } \\
\text { patrón de los } \\
\text { periquimatíes. }\end{array}$ \\
\hline
\end{tabular}




\begin{tabular}{|c|c|c|c|c|c|c|}
\hline & \multicolumn{2}{|c|}{ Caries Dental } & \multicolumn{2}{|c|}{ Fluorosis Dental } & \multicolumn{2}{|c|}{$\begin{array}{c}\text { Defectos del Desarrollo no } \\
\text { Fluoróticos }\end{array}$} \\
\hline & No cavitada & Cavitada & $\begin{array}{c}\text { Muy leve a } \\
\text { moderada } \\
\text { (Índice TF 1-7) }\end{array}$ & $\begin{array}{c}\text { Severa } \\
\text { (Índice TF 5-9) }\end{array}$ & $\begin{array}{l}\text { Opacidad/ } \\
\text { Hipominera- } \\
\text { lización }\end{array}$ & Hipoplasia \\
\hline $\begin{array}{l}\text { Distribución en } \\
\text { la dentición }\end{array}$ & $\begin{array}{l}\text { Lesión activa: } \\
\text { fosas y fisuras, } \\
\text { superficies } \\
\text { próximales } \\
\text { debajo del punto } \\
\text { de contacto; } \\
\text { superficies } \\
\text { libres reflejando } \\
\text { posición del } \\
\text { borde marginal. } \\
\text { Lesión inactiva: } \\
\text { ubicada lejos del } \\
\text { margen gingival. }\end{array}$ & $\begin{array}{l}\text { La lesión } \\
\text { ocurre en sitios } \\
\text { de retención } \\
\text { de biofilme: } \\
\text { fosas y fisuras, } \\
\text { superficies } \\
\text { próximales } \\
\text { bajo el punto } \\
\text { de contacto; } \\
\text { superficies } \\
\text { libres reflejando } \\
\text { posición del } \\
\text { borde marginal. }\end{array}$ & $\begin{array}{l}\text { Simétrica } \\
\text { en dientes } \\
\text { homólogos, con } \\
\text { prácticamente } \\
\text { el mismo nivel } \\
\text { de severidad. La } \\
\text { superficie dental } \\
\text { se ve afectada } \\
\text { según el grado } \\
\text { de exposición } \\
\text { sistémica. }\end{array}$ & $\begin{array}{l}\text { Simétrica } \\
\text { en dientes } \\
\text { homólogos. La } \\
\text { superficie dental } \\
\text { se ve afectada } \\
\text { según el grado } \\
\text { de exposición } \\
\text { sistémica. }\end{array}$ & $\begin{array}{l}\text { Ocurre en un } \\
\text { solo diente } \\
\text { (comúnmente } \\
\text { incisivos). } \\
\text { Ocasionalmente } \\
\text { puede bservarse } \\
\text { una distribución } \\
\text { simétrica. }\end{array}$ & $\begin{array}{l}\text { Localizada o } \\
\text { generalizada. } \\
\text { La lesión puede } \\
\text { variar desde una } \\
\text { fina línea a través } \\
\text { de la superficie } \\
\text { dentaria hasta } \\
\text { una ancha banda } \\
\text { de esmalte } \\
\text { defectuoso. }\end{array}$ \\
\hline $\begin{array}{l}\text { Características } \\
\text { histopato- } \\
\text { lógicas }\end{array}$ & $\begin{array}{l}\text { Desmineraliza- } \\
\text { ción } \\
\text { subsuperficial } \\
\text { (origen } \\
\text { bacteriano) }\end{array}$ & $\begin{array}{l}\text { Desmine- } \\
\text { ralización con } \\
\text { pérdida en la } \\
\text { superficie. } \\
\text { Ruptura de } \\
\text { esmalte y } \\
\text { posible invasión } \\
\text { bacteriana de la } \\
\text { dentina. }\end{array}$ & $\begin{array}{l}\text { Hipomine- } \\
\text { ralización } \\
\text { subsuper- } \\
\text { ficial debido a } \\
\text { alteracio-nes en } \\
\text { la maduración } \\
\text { del esmalte }\end{array}$ & $\begin{array}{l}\text { Hipomine- } \\
\text { ralización } \\
\text { subsuperficial } \\
\text { con pérdidas } \\
\text { de áreas } \\
\text { superficiales } \\
\text { correspondientes } \\
\text { a la formación de } \\
\text { fosas. }\end{array}$ & $\begin{array}{l}\text { Hipominerali- } \\
\text { zación } \\
\text { subsuperficial } \\
\text { debido a una } \\
\text { alteración } \\
\text { localizada } \\
\text { (traumática) de la } \\
\text { mineralización. }\end{array}$ & $\begin{array}{l}\text { Perturbación } \\
\text { del desarrollo } \\
\text { del esmalte, } \\
\text { que genera } \\
\text { un contorno } \\
\text { superficial } \\
\text { alterado. La } \\
\text { mineralización del } \\
\text { esmalte puede } \\
\text { verse afectada }\end{array}$ \\
\hline
\end{tabular}




\section{DOCUMENTACIÓN DE CASOS CLÍNICOS DE LA CONDICIÓN EN LA NIÑEZ COSTARRICENSE}

El siguiente conjunto de fotografías caracteriza la amplia gama de situaciones clínicas que se presentan en la niñez costarricense relacionadas con la hipomineralización incisivo molar (Figuras 1, 2, 3, 4, 5 y 6).

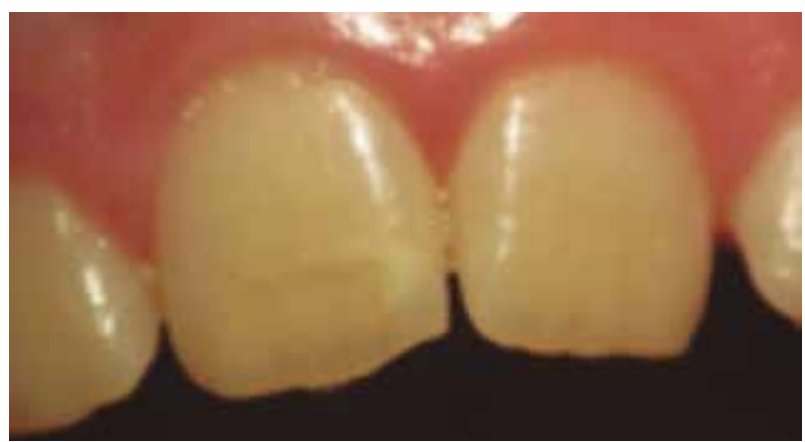

Figura 1. Central superior derecho permanente: opacidad blanquecina unilateral bien delimitada. El esmalte superficial está intacto.

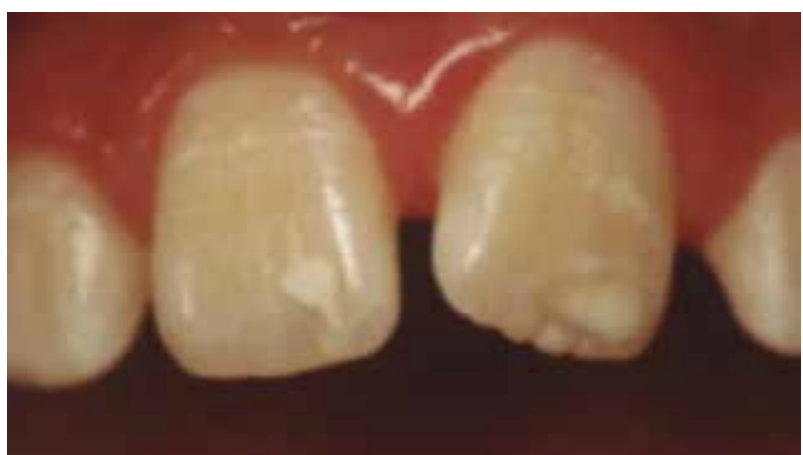

Figura 2. Incisivos centrales superiores permanentes: presencia de hipomineralizaciones bilaterales bien delimitadas con coloración blanquecina.

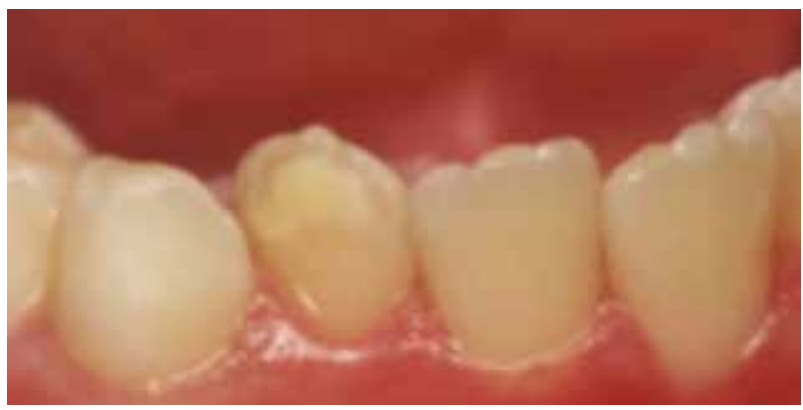

Figura 3. Lateral inferior derecho permanente: amplia opacidad delimitada blanco-amarillenta, fácilmente distinguible del esmalte sano adyacente.

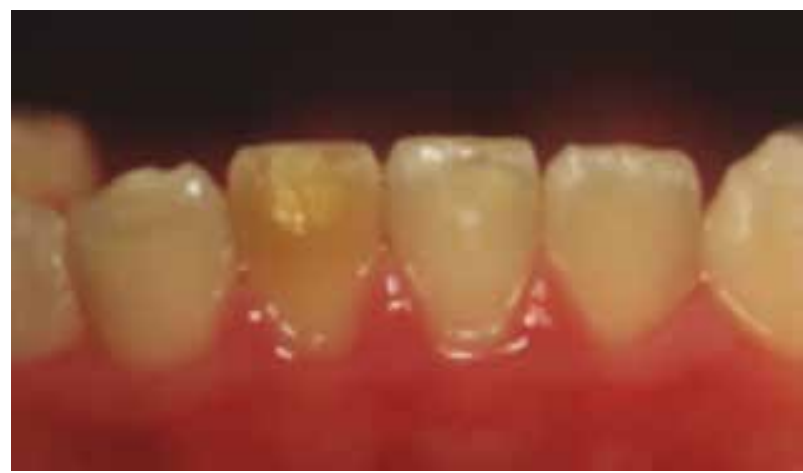

Figura 4. Centrales inferiores permanentes: hipomineralizaciones bilaterales que ejemplifican la variabilidad en sus manifestaciones clínicas. En el central inferior derecho la lesión hipomineralizada es de color amarillento-marrón y se asocia con una hipoplasia. Laterales inferiores: nótese la fluorosis dental con el típico "snow cap"en el borde incisal.

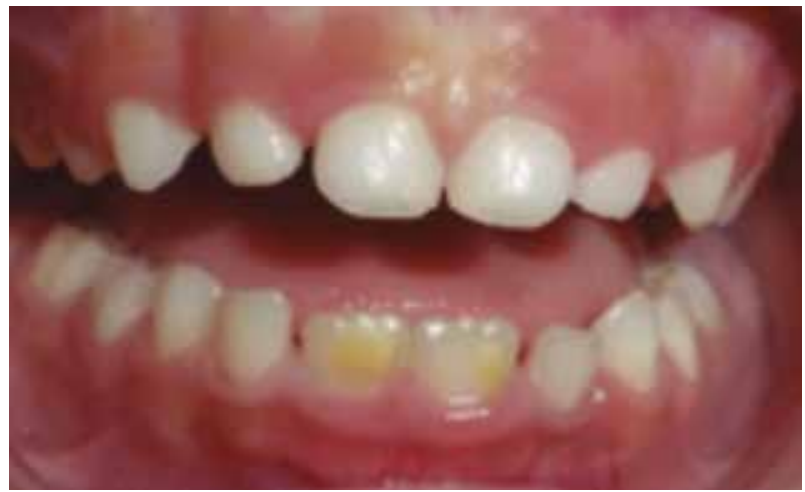

Figura 5. Incisivos centrales inferiores permanentes: presentan lesiones de hipomineralización bilaterales con coloración amarillomarrón en un joven paciente pediátrico.

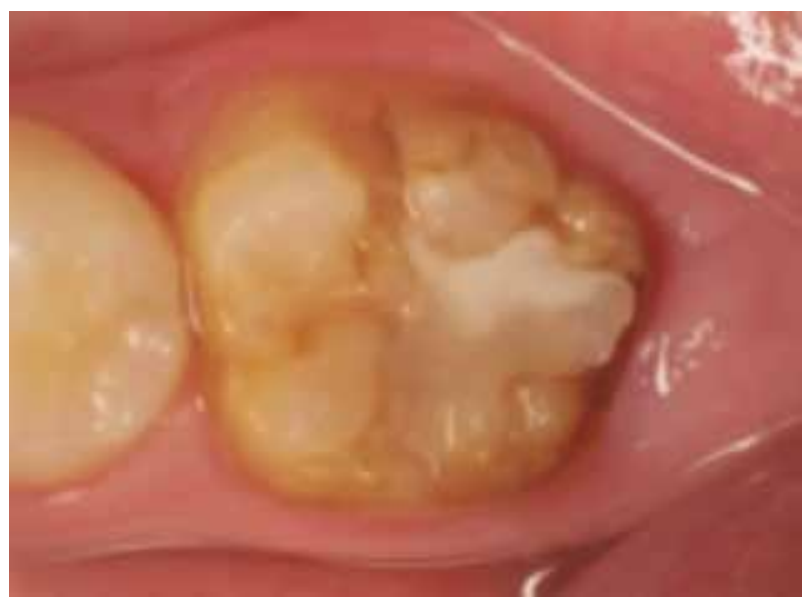

Figura 6. Primer molar permanente inferior izquierdo: amplia hipomineralización asociada con la presencia de caries. Se observa la presencia de una restauración atípica e irregular en deficiente estado. 
DISCUSIÓN

Se pueden resumir las limitaciones actuales para establecer la etiología de HIM de la siguiente forma:

Dificultad para determinar el momento exacto de la aparición del defecto del esmalte y el umbral al que son capaces de responder los ameloblastos.

Incapacidad de determinar con exactitud la alteración sistémica que daña los ameloblastos y, en consecuencia, que da lugar a la hipomineralización.

La imposibilidad de determinar la causa exacta del Síndrome Incisivo Molar hace que, a su vez, sea imposible determinar el período de tiempo de exposición al estímulo que se requiere para que se produzca la alteración de los ameloblastos.

\section{CONCLUSIONES}

Los defectos del esmalte son ampliamente observados en la población pediátrica. Aún así, en Costa Rica se desconoce la prevalencia de HIM en los distintos grupos etáreos de esa población. En la actualidad, la HIM tiene un fuerte impacto en las necesidades de tratamiento odontopediátrico, por la frecuencia y la severidad de las lesiones.

Debido al desconocimiento de la naturaleza y características de la HIM, el tratamiento que se brinda a la condición no es el más adecuado. Las lesiones que se localizan en los primeros molares permanentes presentan, con frecuencia, asociación con procesos de caries dental, lo que dificulta su abordaje terapéutico.

No existe suficiente evidencia que permita establecer un factor etiológico inequívoco por el que la condición ocurre, por lo que su etiología sigue siendo de origen desconocido. Sin embargo, se han descrito una serie de condiciones médicas y ambientales que pueden estar asociadas con la presencia del defecto (12).

\section{RECOMENDACIONES}

Los padres de familia deben ser alertados acerca del riesgo de que sus hijos (as) desarrollen HIM, si durante el embarazo o los primeros años de vida el infante se ve expuesto a alguno(s) de los factores de riesgo descritos en la sección correspondiente, asociados con la condición.

Las características clínicas de HIM alertan acerca de la importancia de manejar la condición con alternativas preventivas aplicadas tempranamente desde el momento mismo del diagnóstico inicial.

La naturaleza de esta patología, asícomo el tratamiento dental adecuado y sus costos, indican claramente la urgente necesidad de realizar investigaciones en Costa Rica para conocer su prevalencia y severidad.

\section{REFERENCIAS}

1. Biondi A, Cortese S, Ortolani A, Argentieri A. Características clínicas y factores de riesgo asociados a Hipomineralización Molar Incisiva. Revista de la Facultad de Odontología (UBA).2010; 25(58):11-15.

2. Osorio J. (2012). Prevalencia de defectos del desarrollo del esmalte en la dentición temporal de niños de 4 a 6 años que asisten al Colegio Instituto Pedagógico Arturo Ramírez Montufar de la Universidad Nacional de Colombia, sede en Bogotáen el año 2011. (Trabajo de grado para optar el título de Estomatóloga Pediátrica y Ortopedista Maxilar). Posgrado Estomatología Pediátrica y Ortopedia Maxilar, Bogotá, Colombia. 2011. 
3. Jälevik B, Dietz W, Norén JG. Scanning electron micrograph analysis of hypomineralized enamel in permanent first molars. International Journal of Paediatric Dentistry. 2005; 15(4):233-240.

4. Jälevik B, Norén JG. Enamel hypomineralization of permanent first molars: a morphological study and survey of possible aetiological factors. International Journal of Paediatric Dentistry. 2000; 10:278-289.

5. Fearne J, Anderson P, Davis GR. 3D X-ray microscopic study of the extent of variations in enamel density in first permament molars with idiopathic enamel hypomineralization. British Dental Journal. 2004; 194:634-638.

6. Rodd HD, Boissonade FM, Day PF. Pulpal status of hypomineralized permanent molars. Journal of Pediatric Dentistry. 2007; 29(6):514-520.

7. Fagrell TG, Lingström P, Olsson S, Steiniger F, NorénJG. Bacterial invasion of dentinal tubules beneath apparently intact but hypomineralized enamel in molar teeth with molar incisor hypomineralization. International Journal of Paediatric Dentistry. 2008; 18(5):333-340.

8. Weerheijm KL, Jälevik B, Alaluusua S. Molar-incisor hypomineralisation. Caries Res. 2001; 35:390-391.

9. Clarkson J. Review of terminology, classifications, and indices of developmental defects of enamel. Advances in Dental Research. 1989; 3:104-109.

10. Weerheijm KL. Molar incisor hypomineralisation (MIH). European Journal Paediatric Dentistry. 2003; 4(3):114-120.

11. Weerheijm KL, Mejàre I. Molar incisor hypomineralization: aquestionnaire inventory of its occurrence in member countries of the European Academy of Paediatric Dentistry (EAPD). International Journal of Paediatric Dentistry. 2003; 13:411-416.
12. CrombieF, Manton D, Kilpatrick N.Aetiology of molar-incisor hypomineralization: a critical review. International Journal of Paediatric Dentistry. 2009 Mar; 19:73-83.

13. García L, Martínez E. Hipomineralización Incisivo-Molar. Estado Actual. Científica Dental. 2010; 7(1):19-28.

14. Mathu-Muju K. Wright JT. Diagnosis and treatment ofmolarincisorhypomineralization. Compendium of Continuing Education in Dentistry. 2006; 27(11):604-610.

15. Jans MA, Díaz MJ, Vergara GC, Zaror SC. Frecuencia y severidad de la hipomineralización molar incisal en pacientes atendidos en las clínicas odontológicas de la Universidad de La Frontera. International Journal of Odontostomatology. 2011; 5(2):133-140.

16. Muratbegovic A, Markovic N, Ganibegovic SM. Molar incisor hypomineralisation in Bosnia and Herzegovina: aetiology and clinical consequences in medium caries activity population. European Archives of Paediatric Dentistry. 2007; 8(4):189-194.

17. Jasulaityte L, Veerkamp JS, Weerheijm KL. Molar incisor hypomineralization: review and prevalence data from the study of primary school children in Kaunas/Lithuania. European Archives of Paediatric Dentistry. 2007; 8(2):87-94.

18. Willmott NS, Bryan RA, Duggal MS. Molarincisor-hypomineralisation: a literature review. European Archives of Paediatric Dentistry. 2008; 9(4):172-189.

19. Jälevik B, Klingberg GA. Dental treatment, dental fear and behaviour management problems in children with severe enamel hypomineralization of their permanent first molars. International Journal of Paediatric Dentistry. 2002; 12(1): 24-32.

20. Jälevik, B., Möller, M. Evaluation of spontaneous space closure and development 
of permanent dentition after extraction of hypomineralized permanent first molars International. Journal of Paediatric Dentistry. 2007; 17:328-335.

21. Kotsanos N, Kaklamanos E, Arapostathis K. Treatment management of first permanent molars in children with Molar-Incisor Hypomineralisation. European Journal Paediatric Dentistry. 2005; 6(4):179-84.

22. Koch G, Hallosten AL, Ludvigsson $\mathrm{N}$, Hansson BO, Holst A, Ullbro C. Epidemiologic study of idiopathic enamel hypomineralization in permanent teeth of Swedish children. Community Dentistry and Oral Epidemiology. 1987; 15:279-285.

23. William V, Messer LB, Burrow MF. Molar incisor hypomineralization: review and recommendations for clinical management. Journal of Pediatric Dentistry. 2006; 28(3): 224-232.

24. Fayle SA. Molar incisor hypomineralization: restorative management. European Journal Paediatric Dentistry. 2003; 4(3):121-126.

25. Ivanovic M, Zivojinovic V, Markovic D, Sindolic M. Treatment Options for Hipomineralized First Permanent Molars and Incisors. Serbian Dental Journal. 2006; 53:174-180.

26. Preusser SE, Ferring V, Wleklinski C, Wetzel WE. Prevalence and severity of molar incisor hypomineralization in a region of Germany -a brief communication. Journal of Public Health Dentistry. 2007; 67:148-151.

27. Lygidakis NA, Dimou G, Briseniou E. Molar-Incisor-Hypomineralisation (MIH). Retrospective clinical study in Greek children. Prevalence and defect characteristics. European Archives of Paediatric Dentistry. 2008; 9(4):200-206.

28. Feltrin J, Jeremias F, Da Costa C, Cilense A, Loiala R, Zuanonb dos Santos-Pinto L. Hipomineralización de incisivos y molares: diagnóstico diferencial. Acta Odontológica Venezolana. 2011; 49(3):1-8.
29. Lygidakis N, Wong F, Jalevik B, Vierrou A, Alaluusua S, Espelid I. Best Clinical Practice Guidance for clinicians dealing with children presenting with Molar-IncisorHypomineralisation (MIH) An EAPD Policy Document. European Archives of Paediatric Dentistry. 2010;11 (2):75-81.

30. Pérez T, Maroto M, Martín MC, Barbería E. Hipomineralización incisivo molar (HIM). Una revisión sistemática. The Journal of the American Dental Association. 2010; 5(5):223-228.

31. Chawla N, Messer LB, Silva M. Clinical studies on molar-incisor-hypomineralisation part 1: distribution and putative associations. Eur Arch Paediatr Dent. 2008 Dec; 9(4):180-90.

32. Beentjes V, Weerheijm KL, Groen HJ. Factors involved in the aetiology of MolarIncisor Hypomineralisation (MIH). European Journal Paediatric Dentistry. 2002;1: 9-13.

33. Brook AH, Smith JM. The aetiology of developmental defects of enamel: a prevalence and family study in East London, U.K. Connective Tissue Research. 1998; 39:151-156.

34. Everett ET, McHenry MAK, Reynolds N, Eggertsson H, Sullivan J, Kantmann C, Martinez-Mier EA, Warrick JM, Stookey GK. Dental fluorosis: variability among different inbred mouse strains. Journal of Dental Research. 2002; 81:794-798.

35. Whatling R, Fearne JM. Molar incisor hypomineralization: a study of aetiological factors in a group of UK children.International Journal of Paediatric Dentistry. 2008; 18(3):155-162.

36. Jan J, Vrbic V. Polychlorinated biphenyls cause developmental enamel defects in children. Caries Res. 2000; 34:469-473.

37. Alaluusua S, Lukinmaa PL, Koskimies M, Pirinen S, Holtta P, Kallio M, Holttinen T, SalmenperäL. Developmental dental defects associated with long breast feeding. European Journal of Oral Sciences. 1996; 104:493-497. 
38. Beltrí P, Barbería E, Polanco I, Planells P. Estudio comparativo de las anomalías del esmalte dentario y caries en niños con enfermedad celíaca y controles. Odontología Pediátrica. 2004; 12:118-122.

39. Jälevik B, Klingberg G, Barregard L, Norén JG. The prevalence of demarcated opacities in permanent first molars in a group of Swedish children. Acta Odontológica Scandinávica. 2001; 59:255-260.

40. Laisi S, Ess A, Sahlberg C, Arvio P, Lukinmaa PL, Alaluusua S. Amoxicillin may cause Molar Incisor Hypomineralization. Journal of Dental Research. 2009; 88(2):132-136.

41. Alaluusua S. Aetiology of molar-incisor hypomineralisation: a systematic review.
European Archives of Paediatric Dentistry. 2010; 11(2):53-58.

42. Fejerskov O, Kidd E. Dental Caries: The Disease and Its Clinical Management.(2 ed). John Wiley \& Sons; 2008.

43. Petrou M, Giraki M, Bissar A, Wempe C, Schafer M, Schiffner U, Beikler T, Schulte A, Splieth C. Severity of MIH findings at tooth surface level among German school children. European Archives of Paediatric Dentistry. 2015; 16(3):271-276.

44. Scheffel DS, Jeremias F, Fragelli CB, SantosPinto LM, Hebling J, de Oliveira OB. Esthetic dental anomalies as motive for bullying in schoolchildren. European Journal Dentistry. 2014; 8(1):124-128. 